\title{
DEMOCRACIA E CONSTITUCIONALISMO, POLÍTICAS PÚBLICAS E DIREITOS SOCIAIS: A CONTRIBUIÇÃO DO PODER JUDICIÁRIO PARA A PROMOÇÃO DE UMA JUSTIÇA DISTRIBUTIVA
}

DEMOCRACY AND CONSTITUTIONALISM, PUBLIC POLICIES AND SOCIAL RIGHTS: THE CONTRIBUTION OF THE JUDICIARY TO PROMOTE A DISTRIBUTIVE JUSTICE

Renan Lucas Dutra Urban ${ }^{1}$

ISSUE DOI: $10.21207 / 1983.4225 .335$

\section{RESUMO}

O trabalho explora o tema da judicialização dos direitos sociais. O problema enunciado é a incapacidade financeira do Estado para prover todas as prestações positivas que compõem o objeto desses direitos, bem como a ilegitimidade democrática do Poder Judiciário para sindicar políticas públicas e decidir sobre escolhas orçamentárias. O objetivo geral é investigar o papel das instituições na formulação e execução das políticas sociais, à luz de um modelo deliberativo de democracia. Com ênfase nas dimensões analítica e normativa da dogmática jurídica, defende-se a ideia de que os diálogos institucionais e a participação democrática no controle das políticas públicas podem maximizar o potencial das decisões judiciais

\footnotetext{
${ }^{1}$ Mestrando em Direito pela Universidade Estadual Paulista "Júlio de Mesquita Filho" UNESP. Graduado em Direito pela UNESP. Membro do "Núcleo de Pesquisas Avançadas em Direito Processual Civil Brasileiro e Comparado" - NUPAD/UNESP. Advogado.
} 
para promover alguma forma de transformação social, especialmente em favor dos grupos marginalizados e menos favorecidos.

Palavras-chave: Direitos Sociais. Políticas Públicas. Poder Judiciário. Diálogo institucional. Participação democrática.

\section{ABSTRACT}

The paper explores the theme of the judicialization of social rights. The problem is the financial inability of the State to provide all the positive benefits that make up the object of these rights, as well as the democratic illegitimacy of the Judiciary to organize public policies and decide on budget choices. The general objective is to investigate the role of institutions in the formulation and implementation of social policies, in the light of a deliberative model of democracy. With an emphasis on the analytical and normative dimensions of legal dogma, the idea is defended that institutional dialogues and democratic participation in the control of public policies can maximize the potential of judicial decisions to promote some form of social transformation, especially in favor of groups Marginalized and disadvantaged.

Keywords: Social Rights. Public policy. Judicial power. Institutional dialogue. Democratic participation.

\section{INTRODUÇÃO}

Os direitos sociais são direitos positivos, na medida em que dependem de uma postura ativa do Poder Público para que sejam efetivados. Ordinariamente, as prestações materiais exigidas para a realização desses direitos são providas por políticas públicas universalistas, que definem o que atender (as necessidades públicas), quem atender (os destinatários) e em que extensão atender (as contingências sociais), em detrimento de outras demandas de interesse geral. Como a realização dos direitos sociais é custosa, e os recursos financeiros públicos são escassos, os atos que decidem pela implementação de determinada política pública 
trazem sempre consigo um trade-off, isto é, uma escolha disjuntiva que não escapa de ser trágica (tragic choices). ${ }^{2}$

O pensamento liberal tradicional classificou como próprias dos órgãos de representação popular as tarefas de planejar, elaborar e executar políticas públicas (“doutrina da questão política”). O constitucionalismo tradicional, na esteira dessa doutrina liberal, fez competir aos Poderes Políticos a implementação de tais políticas, submetendo exclusivamente ao juízo discricionário deles a escolha dos meios de ação política e a definição das necessidades sociais a serem satisfeitas. ${ }^{3}$ Presentemente, porém, num contexto de constitucionalização do direito infraconstitucional e de judicialização das matérias políticas, é impossível exagerar o peso da participação do Judiciário no ciclo de efetivação das políticas públicas. ${ }^{4}$ Mais do que simplesmente fiscalizar sua regular constituição e execução, autoridades judicantes têm exercido um papel decisivo no próprio processo de formulação dos programas governamentais, influenciando as decisões tomadas no âmbito dos Poderes Legislativo e Executivo. ${ }^{5}$

Se, por um lado, a existência de um grande número de decisões judiciais condenando o Poder Público a entregar prestações fáticas sinaliza a conquista de normatividade das disposições constitucionais definidoras dos direitos sociais, por outro, as diversas críticas lançadas contra essas decisões colocam um ponto de interrogação sobre a legitimidade e os limites da atuação do Judiciário nessa matéria. Nesse particular, podem ser apontadas duas dificuldades basicamente.

A primeira se liga à própria compreensão da natureza dos direitos sociais e da função por eles desempenhada no espaço democrático, em

\footnotetext{
2 AMARAL, Gustavo. Direito, escassez \& escolha: em busca de critérios jurídicos para lidar com a escassez de recursos e as decisões trágicas. Rio de Janeiro: Renovar. 2001. p. 150 .

${ }^{3}$ LOPES, José Reinaldo de Lima. Em torno da "reserva do possível". In: SARLET, Ingo Wolfgang; TIMM, Luciano Benetti (Orgs.). Direitos fundamentais, orçamento e "reserva do possível". 2. ed. Porto Alegre: Livraria do Advogado, p. 155-173, 2010. p. 163. ${ }^{4}$ Como adverte Matthew Taylor, a afirmação da participação ativa do Judiciário no processo de implementação de políticas públicas não traduz constatação simples de assimilada, antes pelo contrário, "é mais complicada do que parece, especialmente no contexto latino-americano, em que especialistas levaram muitos anos após as transições dos regimes militares para direcionar sua atenção para o papel dos tribunais nas políticas públicas e na governabilidade" (TAYLOR, Matthew M. O Judiciário e as políticas públicas no Brasil. Revista de Ciências Sociais, Rio de Janeiro, v. 50, n. 2, p. 229-257, 2007. p. 229). 5 TAYLOR, Matthew M. O Judiciário e as políticas públicas no Brasil. Revista de Ciências Sociais, Rio de Janeiro, v. 50, n. 2, p. 229-257, 2007. p. 230.
} 
virtude das diferentes abordagens filosóficas, políticas, econômicas etc. que podem ser realizadas a respeito deles. Liberalismo, utilitarismo e consequencialismo são exemplos de formulações que têm algo a dizer sobre esses direitos. A segunda dificuldade, que pode ser apontada como um reflexo da primeira, é a concernente à justiciabilidade desses direitos e, bem assim, do papel das instituições e da sociedade civil na elaboração, execução e controle das respectivas políticas públicas.

Este texto explora precisamente o tema da justiciabilidade dos direitos sociais. O objetivo principal é discutir de que modo o Poder Judiciário pode contribuir para a realização de uma justiça distributiva, a partir de sua atividade de controle das omissões estatais e de sindicação das políticas públicas. Com ênfase nas dimensões analítica e normativa da abordagem dogmática, ${ }^{6}$ defende-se a ideia, aqui, de que um maior diálogo entre as instituições acerca de políticas públicas pode maximizar o potencial das decisões judiciais para promover alguma forma de transformação social, especialmente em favor dos grupos socialmente excluídos.

\section{DIREITOS DE DEFESA E DIREITOS A PRESTAÇÕES. A JUSTICIABILIDADE DOS DIREITOS SOCIAIS}

Os direitos fundamentais são, basicamente, direitos de defesa ou direitos a prestações. ${ }^{7}$ Os direitos de defesa, também chamados direitos de resistência ou negativos, têm como objeto uma ação negativa do destinatário - notadamente o Estado. ${ }^{8}$ Qualquer que seja a espécie a que per-

\footnotetext{
${ }^{6} \mathrm{Cf}$., acerca da distinção entre método de trabalho e abordagem metodológica, bem como sobre as dimensões da pesquisa dogmática, SILVA, Virgílio Afonso da. A constitucionalização do direito: os direitos fundamentais nas relações entre particulares. São Paulo: Malheiros, 2008. p. 25-26.

7 Os direitos fundamentais são, tradicionalmente, direitos contra o Estado. Porém, no âmbito da sua eficácia horizontal, também podem produzir efeitos nas relações entre particulares. Cf., sobre o assunto, SILVA, Virgílio Afonso da. A constitucionalização do direito: os direitos fundamentais nas relações entre particulares. São Paulo: Malheiros, 2008.

${ }^{8}$ Cf., sobre a divisão dos direitos fundamentais em direitos de defesa (ou direitos a ações negativas) e direitos prestacionais (ou direitos a ações positivas), ALEXY, Robert. Teoria dos direitos fundamentais. Tradução de Virgílio Afonso da Silva. São Paulo: Malheiros, 2008. p. 180-218. Na literatura brasileira, ver, por exemplo, a classificação proposta por SARLET, Ingo Wolfgang. A eficácia dos direitos fundamentais: uma teoria geral dos
} 
tencem - direitos ao não embaraço de ações, direitos à não afetação de características e situações e direitos à não eliminação de posições jurídicas $^{9}-$, a consequência jurídica desses direitos consiste sempre num não fazer, numa omissão. ${ }^{10}$ Associados ao contexto histórico e filosófico de fundação do Estado Liberal, os direitos de defesa aproximam-se, em ampla medida, da categoria dos direitos fundamentais de $1^{\text {a }}$ geração/dimensão, composta pelas liberdades civis e políticas. Na tradicional classificação de Georg Jellinek, são os direitos de status negativo ou $l i$ bertatis. $^{11}$

Os direitos a prestações, por sua vez, cumprem a função de assegurar aos indivíduos a proteção de determinada situação jurídica ou o desfrute de uma utilidade concreta. Seu objeto consiste na entrega de prestações normativas ou fáticas, correspondentes aos direitos prestacionais em sentido amplo ou em sentido estrito respectivamente. ${ }^{12}$ Eles definem, dessa maneira, uma obrigação positiva para o Estado, relacionada ao dever de implementação de políticas públicas sociais e econômicas. Assim, enquanto os direitos de defesa visam, basicamente, a proteger o indivíduo contra as ingerências do Estado em seu âmbito de liberdade pessoal, reclamando deste a adoção de comportamentos negativos, os direitos prestacionais voltam-se para a realização da igualdade material, e impõem ao Estado a adoção de uma postura ativa, isto é, interventiva nas esferas econômica e social. ${ }^{13}$

A singularidade dos direitos a prestações reside, portanto, na obrigação dirigida ao Poder Público de criar os pressupostos normativos e

direitos fundamentais na perspectiva constitucional. 10. ed. Porto Alegre: Livraria do Advogado, 2009. p. 162-207.

${ }^{9}$ ALEXY, Robert. Teoria dos direitos fundamentais. Tradução de Virgílio Afonso da Silva. São Paulo: Malheiros, 2008. p. 196-201.

${ }^{10}$ Cf. BOROWSKI, Martin. La estructura de los derechos fundamentales. Tradução de Carlos Bernal Pulido. Bogotá: Universidad Externado de Colombia, 2003. p. 111.

${ }^{11}$ Cf ALEXY, Robert. Teoria dos direitos fundamentais. Tradução de Virgílio Afonso da Silva. São Paulo: Malheiros, 2008. p. 254-275.

${ }^{12}$ Cf. SARLET, Ingo Wolfgang. A eficácia dos direitos fundamentais: uma teoria geral dos direitos fundamentais na perspectiva constitucional. 10. ed. Porto Alegre: Livraria do Advogado, 2009. p. 184-189.

${ }^{13}$ MIRANDA, Jorge. Manual de direito constitucional. 4. ed. Coimbra: Coimbra, t. IV, 1998. p. 40. 
materiais para a fruição das situações jurídicas por eles protegidas. ${ }^{14} \mathrm{Na}$ qualidade de elementos fundamentais do processo de construção e desenvolvimento do Estado Social, tais direitos associam-se ao status positivo ou civitatis, e confundem-se, de certa forma, com a categoria dos direitos fundamentais de $2^{\mathrm{a}}$ geração (direitos sociais, econômicos e culturais). ${ }^{15}$

O debate sobre a eficácia e a efetividade dos direitos fundamentais e, particularmente, dos direitos prestacionais, é bastante intenso. Embora já tenha se tornado corrente a afirmação de que não há norma inscrita na Constituição que esteja privada de imperatividade e, portanto, de eficácia, ${ }^{16}$ questiona-se se o Poder Público pode ser obrigado pelo Poder Judiciário a adotar as medidas necessárias para a realização desses direitos. No que toca aos direitos a prestações materiais ou fáticas, em particular - e aos direitos sociais, em especial -, é possível identificar duas recorrentes objeções à possibilidade de que, com base nas disposições constitucionais em que assentados, o Estado seja judicialmente forçado a prestar os correspondentes serviços públicos.

O primeiro argumento, frequentemente suscitado em desfavor da justiciabilidade dos direitos prestacionais sociais, diz respeito à eficácia das normas constitucionais que os preveem. A tese subjacente a este argumento é a de que os direitos prestacionais estão definidos em enunciados dotados de baixa densidade normativa e de elevado índice de indeterminação semântica, razão pela qual dependem de uma ação estatal para que possam ser exigidos judicialmente. Afirma-se, nesse sentido, que os direitos sociais - à diferença dos direitos de defesa, geralmente definidos

\footnotetext{
${ }^{14}$ KRELL, Andreas J. Direitos sociais e o controle judicial no Brasil e na Alemanha: os (des)caminhos de um direito constitucional "comparado". Porto Alegre: Sergio Antonio Fabris Editor, 2002. p. 19.

${ }^{15}$ A identificação dos direitos de defesa com os direitos de $1^{\text {a }}$ geração e dos direitos prestacionais com os direitos de $2^{a}$ geração não é rigorosamente exata. De fato, nem todos os direitos civis e políticos são negativos: muitos deles são preponderantemente prestacionais, isto é, veiculam uma obrigação de fazer ao Poder Público - como, por exemplo, o direito dos partidos políticos a recursos do fundo partidário e acesso à propaganda política gratuita nos meios de comunicação. Por outro lado, nem todos os direitos sociais, econômicos e culturais são prestacionais. $\mathrm{O}$ direito de greve e a liberdade de sindicalização são exemplos de direitos de $2^{a}$ geração que impõem deveres negativos ao Estado. Cf., no ponto, SARLET, Ingo Wolfgang. A eficácia dos direitos fundamentais: uma teoria geral dos direitos fundamentais na perspectiva constitucional. 10. ed. Porto Alegre: Livraria do Advogado, 2009. p. 159-162.
}

${ }^{16}$ SILVA, José Afonso da. Aplicabilidade das normas constitucionais. 7. ed. São Paulo: Malheiros, 2009. p. 81. 
em normas constitucionais com aplicabilidade imediata (eficácia plena ou imediata) - estão consagrados em normas programáticas, dotadas de uma aplicabilidade apenas mediata (eficácia limitada). ${ }^{17}$ Nesses termos, não seria possível postular, originariamente das normas constitucionais definidoras dos direitos prestacionais, o fornecimento de um bem ou a prestação de um serviço; para que os Poderes Políticos possam ser compelidos a adimplir as respectivas prestações materiais, seria antes necessária uma definição legislativa acerca do que é juridicamente devido em relação a tais direitos. ${ }^{18}$

O segundo argumento, geralmente colocado como óbice à exigibilidade dos direitos prestacionais, possui natureza pragmáticofinanceira, e volta-se para os custos financeiros que decorrem da efetivação desses direitos (cost of rights). Fundado no truísmo de que políticas públicas demandam recursos financeiros para que sejam implementadas, e de que recursos financeiros públicos são escassos, tal argumento geralmente é invocado para o fim de enfatizar a dimensão econômica de destaque dos direitos prestacionais, no sentido de que dependem da existência de disponibilidades financeiras de grande monta para que possam se efetivar. ${ }^{19}$ Sustenta-se, nesse particular, que a entrega das prestações materiais submete-se a escolhas político-governamentais de natureza disjuntiva, que definem, na lei orçamentária, as necessidades públicas a serem atendidas e os respectivos serviços públicos a serem prestados. Em outras palavras, as escolhas de alocação orçamentária, porque coordenam e selecionam os gastos a serem realizados pelos Poderes Públicos, consubstanciam-se no orçamento; logo, segundo essa linha, é dentro da prática orçamentária, na via democrático-deliberativa, que se localiza o campo próprio para a realização das opções acerca da entrega de tal ou qual prestação, correspondente à efetivação de tal ou qual direito prestacional. ${ }^{20}$

\footnotetext{
${ }^{17}$ SILVA, José Afonso da. Aplicabilidade das normas constitucionais. 7. ed. São Paulo: Malheiros. 2009, p. 140.

${ }^{18}$ SARLET, Ingo Wolfgang. A eficácia dos direitos fundamentais: uma teoria geral dos direitos fundamentais na perspectiva constitucional. 10. ed. Porto Alegre: Livraria do Advogado, 2009. p. 289-291.

${ }^{19}$ CANOTILHO, J.J. Gomes. Estudos sobre direitos fundamentais. Coimbra: Coimbra Ed., 2008. p. 106.

${ }^{20}$ Nesse sentido, cf. TORRES, Ricardo Lobo. Tratado de direito constitucional financeiro e tributário: o orçamento na Constituição. 2. ed. Rio de Janeiro: Renovar, 2000, v. 5. p. 174-178.
} 
A questão do custo dos direitos conduz à problemática da chamada "reserva do possível", examinada na sequência.

\section{O CUSTO DOS DIREITOS E A DIMENSÃO ECONÔMICA DE DESTAQUE DOS DIREITOS SOCIAIS. A "RESERVA DO POSSÍVEL"}

A onerosidade do processo de efetivação dos direitos fundamentais não é característica exclusiva dos direitos a prestações materiais. Também os direitos de defesa - e os direitos a prestações jurídiconormativas - implicam gastos públicos, decorrentes sobretudo da necessidade de criação e de manutenção dos pressupostos materiais garantidores do exercício desses direitos. ${ }^{21}$

Não há dúvida, por exemplo, de que é necessário um conjunto de dispêndios para a organização e manutenção da Polícia e dos Bombeiros, para se proteger determinados bens, como a vida e a propriedade; o mesmo pode ser dito relativamente ao cadastramento eleitoral e à realização das eleições, eventos que, não obstante onerosos, afiguram-se necessários para o exercício dos direitos políticos. De modo análogo, é evidente que parte de toda a atuação do Poder Judiciário - cujo regular funcionamento imprescinde, como se sabe, de vultosos aportes financeiros volta-se exatamente para a proteção dos direitos de defesa, como a propriedade, a segurança, a imagem, a honra etc. ${ }^{22}$

Os exemplos são inúmeros, e não convém alongá-los. A ideia enunciada é razoavelmente tranquila e chega mesmo a ser intuitiva: todos os direitos, e não só os prestacionais, possuem uma dimensão econômica. Por que o argumento do custo dos direitos, então, é geralmente suscitado apenas em desfavor dos direitos prestacionais (sociais)? Há, basicamente, duas respostas para essa questão.

Em primeiro lugar, os direitos a prestações materiais - precisamente porque a efetivação desses direitos pressupõe o oferecimento de serviços e/ou a distribuição de bens - demandam a mobilização de maio-

\footnotetext{
${ }^{21}$ Cf., nesse sentido, ABRAMOVICH, Víctor; COURTIS, Christian. Los derechos sociales como derechos exigibles. Madrid: Trotta, 2002.

${ }^{22}$ Cf. BARCELLOS, Ana Paula de. Eficácia jurídica dos princípios constitucionais: o princípio da dignidade da pessoa humana. 2. ed. Rio de Janeiro: Renovar, 2008. p. 264265.
} 
res valores em relação ao necessário para a satisfação dos direitos de defesa. A realização dos direitos prestacionais custa dinheiro - custa muito dinheiro. ${ }^{23}$ Daí falar-se, pois, que a diferença entre os direitos sociais e as liberdades individuais, no aspecto econômico-financeiro, não é de natureza, mas de grau: ambas as espécies de direitos fundamentais reclamam dispêndios para que sejam efetivados, mas aqueles, de uma forma geral, demandam recursos financeiros em volume maior que o necessário para a satisfação destas. ${ }^{24}$

Em segundo lugar, os direitos de defesa e direitos a prestações significam distintos custos, dado o modo diferente de realização de cada um deles. Veja-se, nesse sentido, que os direitos prestacionais sociais, pelo fato de que cumprem uma função eminentemente (re)distributiva, têm custos que variam de acordo com a necessidade de cada indivíduo. Com afirma José Reinaldo de Lima Lopes, "[...] ao garantir um direito à saúde ou um direito à educação, o que se garante é realmente uma prestação positiva que será diferente conforme a condição social e pessoal de cada indivíduo ou grupo". ${ }^{25}$ Por outro lado, os custos representados pelos direitos de defesa, como os decorrentes do funcionamento do aparelho judiciário ou policial, por exemplo, não têm relação direta com os interesses que se quer defender: os valores decorrentes de um processo judicial não possuem comunicação necessária com o real benefício que se venha a obter ao final desse processo; da mesma forma, os recursos demandados para a prestação dos serviços de segurança pública não variam consideravelmente em função dos interesses ou bens que, por meio desses serviços, são protegidos. Além disso, o objeto da prestação, relativamente aos custos que importam aos cofres públicos, é diferente nos direitos prestacionais típicos ( $v . g$., direito à saúde) em comparação aos direitos de defesa (v. g., direito à propriedade): nestes, a prestação é para a proteção de determinado bem que pode ter sido adquirido no mercado; naqueles, a prestação é o próprio serviço (que pode ser prestado dentro ou fora do merca-

\footnotetext{
23 “" [...] hoje, como ontem, os direitos sociais, econômicos e culturais despejam um problema inquestionável: custam dinheiro, custam muito dinheiro" (CANOTILHO, José Joaquim Gomes. Estudos sobre direitos fundamentais. São Paulo: Revista dos Tribunais, 2008. p. 106).

${ }^{24}$ Cf. BARCELLOS, Ana Paula de. Eficácia jurídica dos princípios constitucionais: o princípio da dignidade da pessoa humana. 2. ed. Rio de Janeiro: Renovar, 2008. p. 265.

${ }^{25}$ LOPES, José Reinaldo de Lima. Em torno da "reserva do possível”. In: SARLET, Ingo Wolfgang; TIMM, Luciano Benetti (orgs.). Direitos fundamentais, orçamento e "reserva do possível". 2. ed. Porto Alegre: Livraria do Advogado, 2010. p. 157-158.
} 
do), que o Estado oferece à sociedade, universal e igualitariamente, por intermédio das respectivas políticas púbicas. ${ }^{26}$

Há razões suficientemente fortes, portanto, para se concluir que é no âmbito dos direitos prestacionais que o "fator custo" assume sua feição mais destacada, enquanto obstáculo à efetivação dos direitos fundamentais.

Como consequência, é dentro da esfera dos direitos prestacionais que se coloca e se discute, com muito mais ênfase, a questão da relevância econômica desses direitos como obstáculo para sua efetivação. Reverbera a doutrina, dessa maneira, a ideia de "neutralidade" econômico-financeira dos direitos de defesa, no sentido de que - apesar do impacto para os cofres públicos que também decorre da realização desses direitos - a tutela jurisdicional das liberdades públicas não costuma estar condicionada a uma conjuntura econômica favorável ou à existência de disponibilidades financeiras estatais. ${ }^{27} \mathrm{Ou}$ seja, não é corriqueiro que se levante, contra a efetivação dos direitos de defesa, a objeção da inexistência ou insuficiência de recursos financeiros públicos. Com efeito, é geralmente em desfavor da justiciabilidade dos direitos a prestações materiais (e, especialmente, dos direitos sociais) que o problema da "reserva do financeiramente possível" é discutido e suscitado.

A seguir, breve exposição sobre o argumento da reserva do possível, sua origem e a forma como tem sido invocado no Brasil.

A expressão "reserva do possível" foi cunhada pela jurisprudência alemã - Vorbehalt des Möglichen -, em paradigmática decisão proferida pela Corte Constitucional Federal em que se entendeu que os direitos às prestações materiais públicas estão situados dentro da reserva do possível na medida em que sujeitos a um parâmetro de razoabilidade,

\footnotetext{
26 "Note-se a diferença da fórmula: 'art. $5^{\circ}$ - XXII - é garantido o direito de propriedade'; 'art. 196. A saúde é direito de todos e dever do Estado, garantido mediante políticas sociais e econômicas que visem a redução do risco de doença e de outros agravos e o acesso universal igualitário às ações e serviços para sua promoção'. O Estado não se obriga a dar acesso à propriedade (de que bens?) a todos, mas a garantir que os que gozam da propriedade não serão esbulhados. Já quanto à saúde o Estado ficou obrigado a garanti-la, mas, claro, mediante políticas sociais e econômicas, não mediante concessões individuais" (LOPES, José Reinaldo de Lima. Em torno da "reserva do possível". In: SARLET, Ingo Wolfgang; TIMM, Luciano Benetti (orgs.). Direitos fundamentais, orçamento e "reserva do possível”. 2. ed. Porto Alegre: Livraria do Advogado, 2010. p. 158-159).

${ }^{27}$ Nesse sentido, Cf. SARLET, Ingo Wolfgang. A eficácia dos direitos fundamentais: uma teoria geral dos direitos fundamentais na perspectiva constitucional. 10. ed. Porto Alegre: Livraria do Advogado, 2009. p. 285.
} 
isto é: àquilo que se pode, de maneira racional, esperar da sociedade. ${ }^{28}$ Trasladou-se para o Direito, a partir desta decisão, a tese do "Limite do Orçamento", cujo significado, basicamente, resume-se nisto: "[...] todo orçamento possui um limite que deve ser utilizado de acordo com as exigências de harmonização econômica geral". ${ }^{29}$

Na célebre decisão firmada pela Corte alemã, que pôs fim ao assim conhecido caso numerus clausus (BverfGE ${ }^{\circ}$ 33, S. 333), a tese da reserva do possível foi invocada como um limite à eficácia do direito de acesso ao ensino superior, para denotar a impossibilidade de se criar, nas Universidades, um número de vagas suficiente para atender a todos os postulantes. Nos termos da solução dada ao caso, a fixação de um número limitado de vagas para o curso de Medicina da Universidade da Bavária não configura violação de obrigação constitucional, uma vez que o Estado só está obrigado às prestações condizentes com os "limites do razoável".

Como se vê, o argumento da reserva do possível foi utilizado, na origem, com base naquilo que fora considerado "razoável" ou "proporcional" pelo Tribunal Constitucional alemão. Não foi a problemática financeira - relativa a um ambiente de escassez absoluta de recursos, de exaustão orçamentária -, portanto, o ponto central de toda a discussão acerca do caso numerus clausus, "[...] mas sim a razoabilidade com que a alocação destes recursos poderia ser [individualmente] demandada". ${ }^{30}$

No Brasil, porém, a reserva do possível assumiu uma feição algo diversa. De fato, a prática jurídico-constitucional brasileira frequentemente recorre à reserva do possível para enfatizar os "custos" desses direitos e, assim, demonstrar a impossibilidade de que sejam tutelados diante da alegação de inexistência ou insuficiência de recursos financeiros públicos. Afirma-se, nesse sentido, que os direitos prestacionais vigem

\footnotetext{
${ }^{28}$ KRELL, Andreas J. Direitos sociais e o controle judicial no Brasil e na Alemanha: os (des)caminhos de um direito constitucional "comparado". Porto Alegre: Sergio Antonio Fabris Editor, 2002. p. 52.

${ }^{29}$ SCAFF, Fernando Facury. Sentenças aditivas, direitos sociais e reserva do possível. In: SARLET, Ingo Wolfgang; TIMM, Luciano Benetti (orgs.). Direitos fundamentais, orçamento e "reserva do possível". 2. ed. Porto Alegre: Livraria do Advogado, 2010. p. 151 (grifo no original).

${ }^{30}$ OLSEN, Ana Carolina Lopes. A eficácia dos direitos fundamentais sociais frente à reserva do possível. 387 f. Dissertação (Mestrado em Direito). Setor de Ciências Jurídicas da Universidade Federal do Paraná. Curitiba, 2006. p. 233.
} 
sob uma reserva do possível na medida em que dependem de uma viabilidade orçamentária ("cofres cheios") para que possam se efetivar. ${ }^{31}$

Além disso, no âmbito doutrinário, tornou-se comum a menção a duas dimensões ou vertentes da reserva do possível, uma fática e outra jurídica. A reserva do possível fática diz respeito à situação de ausência de recursos para a efetivação dos direitos prestacionais. Pressupõe, conforme se afirma, um estado de exaustão financeira, de absoluta impossibilidade econômica (fática) do Estado. ${ }^{32}$ Ad impossibilia nemo tenetur: ninguém está obrigado ao impossível - e o Estado, evidentemente, não foge à regra. ${ }^{33} \mathrm{Em}$ situação de indisponibilidade absoluta de recursos financeiros, o Estado estaria desobrigado de prover os bens e serviços necessários à efetivação dos direitos sociais.

A reserva do possível jurídica, por sua vez, aponta para a ilegitimidade democrática das decisões judiciais que determinam gastos públicos em matéria de direitos sociais. Como se sabe, o Poder Judiciário tem características diversas das dos outros Poderes, uma vez que os agentes políticos que o compõem - os juízes - não são eleitos pelo povo, isto é, não são investidos em suas funções por processos político-majoritários. Ora, as escolhas alocativas possuem um caráter nitidamente político, discricionário, uma vez que "não há um critério único que possa ser empre-

\footnotetext{
${ }^{31}$ Essa diferença de perspectiva deve-se, em boa medida, à absorção das lições doutrinárias de José Joaquim Gomes Canotilho, que deu nova leitura à teoria da reserva do possível alemã. Cf., no ponto, OLSEN, Ana Carolina Lopes. A eficácia dos direitos fundamentais sociais frente à reserva do possível. $387 \mathrm{f}$. Dissertação (Mestrado em Direito). Setor de Ciências Jurídicas da Universidade Federal do Paraná. Curitiba, 2006. p. 237; KRELL, Andreas J. Direitos sociais e o controle judicial no Brasil e na Alemanha: os (des)caminhos de um direito constitucional "comparado". Porto Alegre: Sergio Antonio Fabris Editor, 2002. p. 51: "O português Canotilho vê a efetivação dos direitos sociais, econômicos e culturais dentro de uma 'reserva do possível' e aponta a sua dependência dos recursos econômicos. A elevação do nível de sua realização estaria sempre condicionada pelo volume dos recursos suscetível de ser mobilizado para esse efeito. Nessa visão, a limitação dos recursos públicos passa a ser considerada verdadeiro limite fático à efetivação dos direitos sociais prestacionais".

32 BARCELLOS, Ana Paula de. Eficácia jurídica dos princípios constitucionais: o princípio da dignidade da pessoa humana. 2. ed. Rio de Janeiro: Renovar, 2008. p. 262.

${ }^{33}$ LOPES, José Reinaldo de Lima. Em torno da "reserva do possível". In: SARLET, Ingo Wolfgang; TIMM, Luciano Benetti (orgs.). Direitos fundamentais, orçamento e "reserva do possível". 2. ed. Porto Alegre: Livraria do Advogado, 2010. p. 159.
} 
gado para todas as decisões a serem tomadas". ${ }^{34}$ Além disso, elas possuem um caráter multilateral, na medida em que promovem a apropriação, em favor de algumas pessoas, de bens ou serviços financiados por toda a sociedade. ${ }^{35}$ Diante disso, a reserva do possível jurídica veicula uma objeção contra as decisões judiciais que, sindicando omissões estatais ou políticas públicas, implicam a alocação de recursos financeiros, necessariamente escassos. É invocada, nesse sentido, para afirmar a necessidade de que tais escolhas alocativas sejam determinadas no âmbito dos Poderes Executivo e Legislativo, eleitos democraticamente e sujeitos à prestação de contas e à responsabilização política (accountability).36

Os argumentos contrários à justiciabilidade dos direitos sociais prestacionais - a eficácia limitada das normas constitucionais que os preveem e a reserva do possível, fática e jurídica -, embora relevantes, não necessariamente afastam, em toda e qualquer situação, uma atuação do Poder Judiciário no campo da justiça distributiva. De fato, como afirma Virgílio Afonso da Silva, é possível propugnar que os órgãos julgadores têm legitimidade para controlar políticas públicas e fazer escolhas alocativas e, mesmo assim, sustentar que essa atuação está limitada por uma série de fatores, relacionados às próprias características estruturais do

${ }^{34}$ AMARAL, Gustavo. Direito, escassez \& escolha: em busca de critérios jurídicos para lidar com a escassez de recursos e as decisões trágicas. Rio de Janeiro: Renovar, 2001. p. 114.

${ }^{35}$ WANG, Daniel Wei Liang. Poder Judiciário e participação democrática nas políticas públicas de saúde. $104 \mathrm{f}$. Dissertação (Mestrado em Direito). Faculdade de Direito da Universidade de São Paulo. São Paulo, 2009. p. 16.

${ }^{36}$ Relacionado ao argumento da ilegitimidade democrática dos órgãos julgadores para fazer escolhas alocativas está o da falta de aptidão desses agentes para controlar os programas governamentais destinados a concretizar direitos sociais. Nos termos dessa objeção, a formulação e a execução das políticas públicas constituem um processo complexo, cuja compreensão demanda senso político e alguns conhecimentos técnico-científicos específicos. Assim, por mais bem preparados que sejam os juízes, eles não disporiam das informações e dos conhecimentos necessários para entender a complexidade técnica subjacente às políticas públicas e, mais do que isso, para avaliar o impacto de suas decisões para o orçamento público e para o plano de justiça distributiva encampado pelo governo. Para uma descrição desse último argumento, na perspectiva das críticas à judicialização do direito à saúde, em especial, cf. WANG, Daniel Wei Liang. Poder Judiciário e participação democrática nas políticas públicas de saúde. $104 \mathrm{f}$. Dissertação (Mestrado em Direito). Faculdade de Direito da Universidade de São Paulo. São Paulo, 2009. p. 11-15. 
Poder Judiciário. ${ }^{37}$ A perspectiva do diálogo institucional ajuda a esclarecer o ponto. Confira-se.

\section{PODER JUDICIÁRIO E DELIBERAÇÃO SOBRE DIREITOS FUNDAMENTAIS. A TEỎRIA DO DIÁLOGO INSTITUCIONAL}

$\mathrm{Na}$ doutrina constitucional, não é difícil encontrar menções à existência de uma incompatibilidade ou, quando menos, tensão entre os conceitos de democracia e constitucionalismo. O ponto de sustentação dessa dicotomia é a vinculação, de um lado, da ideia de soberania popular e vontade da maioria ao conceito de democracia, e, de outro, da ideia de limitação do poder e Estado de Direito ao conceito de constitucionalismo. ${ }^{38} \mathrm{O}$ debate acerca da legitimidade da atividade judicial consistente em declarar inválidas as normas e condutas estatais incompatíveis com a Constituição pressupõe exatamente a relação problemática entre esses dois ideais políticos.

A atribuição ao Poder Judiciário da competência para verificar a compatibilidade de leis e atos normativos com a Constituição não é autoevidente, explicável em si. Ordens constitucionais há que nem sequer preveem mecanismos formais de controle de constitucionalidade. E, mesmo nos Estados onde eles existem, geralmente não são poucos os desacordos sobre os limites e as possibilidades das decisões tomadas em sede de jurisdição constitucional. ${ }^{39}$ Não há relação necessária entre a afirmação da supremacia da Constituição e a existência de um controle

\footnotetext{
37 SILVA, Virgílio Afonso da. O Judiciário e as políticas públicas: entre transformação social e o obstáculos à realização dos direitos sociais. In: SOUZA NETO, Cláudio Pereira de; SARMENTO, Daniel. Direitos sociais: fundamentação, judicialização e direitos sociais em espécie. Rio de Janeiro: Lumen Juris. 2008. p. 596.

${ }^{38}$ Nesse sentido, MICHELMAN, Frank I. Brennan and democracy. New Jersey: Princeton University, 1999. p. 4-6. Como exemplo de posição teórica contrária à dicotomia democracia-constitucionalismo e, em particular, à concepção de Michelman, cf. HABERMAS, Jürgen. Constitutional democracy: a paradoxical union of contradictory principles? Political Theory, v. 29, n. 6, p. 766-781, dez. 2001.

${ }^{39}$ HABERMAS, Jürgen. Direito e democracia: entre facticidade e validade. Trad. Flávio Beno Siebeneichler. Rio de Janeiro: Tempo Brasileiro, 1997, v. 1. p. 298.
} 
judicial de constitucionalidade. A escolha por determinado tipo de controle é uma questão de conveniência política, não um imperativo lógico. ${ }^{40}$

As razões (políticas) que se colocam a propósito da necessidade de haver (ou não) um guardião da Constituição - isto é, uma instituição incumbida de dar a última palavra acerca da interpretação constitucional - quase sempre são conduzidas para dentro de uma discussão mais ampla, concernente ao desenho institucional que se deseja consagrar à vista do princípio da separação dos poderes. Essa discussão pode ser estudada desde variadas perspectivas teóricas. No ponto, parece ser suficiente apresentar um dos debates que mais têm chamado a atenção da doutrina contemporânea: a contraposição de ideias de Ronald Dworkin e Jeremy Waldron, correspondentes às noções de fórum dos princípios e maximização da participação popular, respectivamente.

Dworkin defende uma concepção de Estado de Direito centrada na ideia de direitos como um ideal político. Por essa razão, não vê os conceitos de democracia e constitucionalismo como opostos ou conflitantes, mas, bem ao contrário, como ideais que podem estar reciprocamente implicados: o Estado de Direito enriquece a democracia na medida em que garante a existência de um fórum independente, um fórum de princípio, no qual questões de direito - e não de política - são discutidas e decididas. ${ }^{41}$ Aos parlamentos eleitos pelos processos político-majoritários compete tomar decisões sobre como melhor promover o bem-estar da coletividade (policies). Porém, em uma democracia constitucional, há alguns requisitos morais substantivos que não podem ficar à mercê do procedimento majoritário. ${ }^{42}$ Para Dworkin, assim, não procede a objeção segundo a qual falta legitimidade democrática ao Judiciário para sindicar e invalidar as leis e os atos normativos deliberados pelas instâncias políticas; o controle judicial de constitucionalidade (judicial review) legitimase pelo fato de ser Poder o Judiciário o locus por excelência de garantia dos direitos fundamentais contra as maiorias de ocasião.

Se Dworkin sustenta uma teoria democrática de cariz "substantivista", Waldron fornece uma de cariz "procedimentalista". Para Wal-

\footnotetext{
40 TROPER, Michel. The logic of justification of judicial review. International Journal of Constitutional Law, v. 1, n. 1, p. 1063-1080, jan. 2003. p. 104.

${ }^{41}$ DWORKIN, Ronald. Uma questão de princípio. Trad. Luís Carlos Borges. São Paulo: Martins Fontes, 2001. p. 39.

${ }^{42}$ MENDES, Conrado Hübner. Deliberação, separação dos poderes e direitos fundamentais. 267 f. Tese (Doutorado em Ciência Política). Faculdade de Filosofia, Letras e Ciências Humanas da Universidade de São Paulo. São Paulo, 2008. p. 7.
} 
dron, a nota de singularidade das sociedades democráticas é o pluralismo, isto é, a convivência de doutrinas abrangentes as mais diversas. O caráter abrangente destas concepções doutrinárias produz, inevitavelmente, inúmeros pontos de fricção entre elas. A consequência disso é a incidência de um profundo desacordo moral sobre qualquer matéria, aí incluídas as concernentes a direitos fundamentais e justiça. Waldron contesta, desse modo, a legitimidade atribuída a juízes e tribunais para dizer a última palavra sobre questões constitucionais. Na verdade, o desacordo moral, precisamente porque inviabiliza a existência de qualquer critério moral de correção baseado na justiça, bem ou verdade, ${ }^{43}$ impede que se atribua a qualquer instituição o ônus da decisão correta.

Em face da indissolubilidade desse desacordo moral reinante em sociedades pluralistas, é preferível - aduz Waldron - o modelo institucional que atribui às instâncias político-majoritárias a competência para decidir sobre questões envolvendo direitos fundamentais àquele que outorga a órgãos jurisdicionais a competência para fazê-lo. É que, ao reservar a tomada de decisões sobre direitos fundamentais aos representantes democraticamente eleitos, enseja-se a maximização do direito de participação em igualdade de condições dos cidadãos na comunidade - o direito dos direitos -, algo que definitivamente não ocorre quando estas decisões são levadas a cabo por intermédio de uma minoria, a "elite judiciária". ${ }^{4}$

O embate das ideias de Dworkin e Waldron é emblemático dos polos opostos da tradição constitucional preocupada em desenvolver uma teoria da autoridade (“quem decide?"). Ilustra, por assim dizer, o dilema subjacente a uma questão geralmente pensada em termos binários: ou Judiciário ou o Legislativo deve desfrutar da primazia de dar a palavra final sobre direitos fundamentais. Assim, não obstante a existência de inúmeras vertentes teóricas no intervalo entre as posições de Dworkin e Waldron, a literatura hegemônica que debate a legitimidade da revisão judicial costuma enfatizar a necessidade de haver uma autoridade definitiva sobre litígios constitucionais ("última palavra"), propondo ou bem um modelo mais próximo da "supremacia judicial" ou bem um modelo

\footnotetext{
${ }^{43}$ ESTLUND, David. Jeremy Waldron on law and disagreement. Philosophical Studies, v. 99, p. 111-128, 2000. p. 192.

${ }^{44}$ SILVA, Virgílio Afonso da. O STF e o controle de constitucionalidade: deliberação, diálogo e razão pública. Revista de direito administrativo, v. 250, p. 197-227, 2009. p. 204.
} 
mais próximo da "supremacia legislativa". ${ }^{45} \mathrm{O}$ desafio que se coloca nessa matéria, então, é o de desenvolver teorias gradualistas ou intermediárias, que contribuam para o delineamento de modelos alternativos ou que promovam uma conciliação entre estes tipos puros, evitando os inconvenientes que eles apresentam em suas formas isoladas. Modernamente, as propostas desenvolvidas no âmbito das teorias do diálogo têm, de alguma forma, enfrentado a questão.

No contexto da ciência política, as teorias do diálogo quase sempre se localizam debaixo do amplo arco da democracia deliberativa. A construção teórica da democracia deliberativa é feita por uma literatura vasta e diversificada, sendo muitas as versões de seu conceito. Roberto Gargarella, por exemplo, propõe um conceito de democracia deliberativa à vista de duas características que lhe seriam fundamentais: a tomada de decisões após um amplo debate coletivo e a possibilidade de participação e intervenção neste processo decisório de todos quantos possam ser afetados pela decisão. ${ }^{46}$ Joshua Cohen, por sua vez, vincula a noção de uma democracia deliberativa ao ideal de justificação. Para ele, o conceito de democracia deliberativa está enraizado na ideia de fundamentação da decisão coletiva, somente levada a efeito no interior de um processo que privilegia a argumentação pública e o intercâmbio de razões entre cidadãos iguais. ${ }^{47}$

Como se vê, o enfoque deliberativo de democracia associa a ideia de legitimidade de uma decisão à de diálogo e persuasão. Mas, quais as implicações normativas da adoção de um enfoque deliberativo de democracia para o funcionamento de determinado arranjo institucional? Que contribuição este enfoque pode oferecer para a compreensão do papel (a ser) desempenhado por tribunais e parlamentos no interior deste arranjo? As variáveis de legitimidade de uma democracia, responde Conrado Hübner Mendes, não se esgotam no procedimento (input), abrangen-

\footnotetext{
${ }^{45}$ MENDES, Conrado Hübner. Deliberação, separação dos poderes e direitos fundamentais. 267 f. Tese (Doutorado em Ciência Política). Faculdade de Filosofia, Letras e Ciências Humanas da Universidade de São Paulo. São Paulo, 2008. p. 36.

${ }^{46}$ Cf. GARGARELLA, Roberto. Should deliberative democrats defend the judicial enforcement of social rights? In: BESSON, Samantha; MARTÍ, José Luis (Orgs.). Deliberative democracy and its discontents. Aldershot: Ashgate, p. 233-252, 2006. p. 239.

47 Cf. COHEN, Joshua. Deliberation and democratic legitimacy. In: MATREVERS, Derek; PIKE, Jon (Orgs.). Debates in contemporary political philosophy: an anthology. New York: Routledge: Open University, p. 342-360, 2003. p. 346.
} 
do também os resultados (output). ${ }^{48}$ Vale dizer: o princípio democrático não se resume a uma estrutura formal de poder, fundada em uma divisão de competências inflexível. A caracterização de um regime como democrático depende também dos resultados substantivos alcançados pelas instituições que dentro dele se concertam. Daí a relevância da deliberação, que estimula a criação de uma cultura de maior densidade argumentativa, à luz da razão pública. ${ }^{49}$ Nesses termos, quanto maior for a qualidade do processo de deliberação pública, tanto maior será o grau de legitimidade da decisão. O desempenho deliberativo, guiado pela razão pública, é, dessa maneira, o critério contextual e comparativo de aferição da legitimidade das oscilações operadas no âmbito das funções institucionais.

Em face disso, é natural que, em determinadas circunstâncias, "a substância subordine o procedimento, ou seja, que uma instituição que tenha alcançado a resposta compatível com um critério substantivo de legitimidade prevaleça sobre outra", ${ }^{50}$ não obstante a posição formal por elas ocupada no interior do arranjo institucional pré-traçado. A última palavra dada por uma instituição formalmente incumbida de fazê-lo não é uma decisão suficiente em si e tampouco imune a críticas substantivas. Aliás, no contexto das teorias dialógicas, que propugnam a intervenção no debate público de todas as partes potencialmente afetadas pela decisão a ser tomada, parece mesmo impensável cogitar sobre a existência de um guardião da Constituição. ${ }^{51}$ No modelo das teorias do diálogo, não há lugar nem para um monólogo judicial nem para um monólogo legislativo: tribunais e parlamentos têm responsabilidades deliberativas, estão em

\footnotetext{
${ }^{48}$ MENDES, Conrado Hübner. Deliberação, separação dos poderes e direitos fundamentais. 267 f. Tese (Doutorado em Ciência Política). Faculdade de Filosofia, Letras e Ciências Humanas da Universidade de São Paulo. São Paulo, 2008. p. 201.

49 Cf., acerca da ideia de razão pública, RAWLS, John. O liberalismo político. Trad. Dinah de Abreu Azevedo. 2 ed. São Paulo: Ática, 2000. p. 262-306.

${ }^{50}$ MENDES, Conrado Hübner. Deliberação, separação dos poderes e direitos fundamentais. 267 f. Tese (Doutorado em Ciência Política). Faculdade de Filosofia, Letras e Ciências Humanas da Universidade de São Paulo. São Paulo, 2008. p. 201.

${ }^{51}$ GARGARELLA, Roberto. Theories of democracy, the Judiciary, and social rights. In: GARGARELLA, Roberto; DOMINGO, Pilar; ROUX, Theunis (Orgs.). Courts and social transformation in new democracies: an institutional voice for the poor? Aldershot: Ashgate, p. 13-34, 2006. p. 28.
} 
constante interlocução, buscam a persuasão e podem desafiar-se mutuamente. $^{52}$

No âmbito dos países que adotam a fórmula do controle judicial de constitucionalidade, a questão que frequentemente se coloca é a de saber se ele deve ser maximalista ou minimalista, ou seja, se é preferível uma forma forte ou uma forma fraca de revisão judicial. Nesse cenário, é comum encontrar-se menções à necessidade de que, em determinadas circunstâncias, o Judiciário assuma uma postura mais ativista ou, ao revés, uma postura mais autocontida, deferente para com as opções políticas firmadas no âmbito dos procedimentos majoritários. A discussão sobe de ponto no que diz respeito ao chamado controle judicial das omissões estatais, geralmente realizado no contexto da sindicação das políticas públicas voltadas para a promoção dos direitos sociais.

\section{DECISÕES JUDICIAIS E TRANSFORMAÇÃO SOCIAL}

A implementação de políticas públicas constitui processo bastante complexo, e as dificuldades relacionadas à realização dos direitos sociais afetam também os Poderes Políticos, e não apenas o Poder Judiciário. ${ }^{53}$ Além disso, os obstáculos que se apresentam ao Poder Judiciário em matéria de políticas públicas, como já apontado, não impedem que se reconheça a importância das deliberações judiciais para promover alguma forma de transformação social. De fato, juízes e tribunais podem ocupar e frequentemente ocupam - uma posição crucial no debate público sobre direitos prestacionais sociais, contribuindo de maneira direta ou indireta para a realização de uma justiça distributiva.

A contribuição direta se dá nas situações em que os órgãos judicantes deliberam sobre pedidos de concessão de prestações materiais, determinando a adjudicação de um bem ou a prestação de um serviço. ${ }^{54}$

52 Cf. MENDES, Conrado Hübner. Deliberação, separação dos poderes e direitos fundamentais. 267 f. Tese (Doutorado em Ciência Política). Faculdade de Filosofia, Letras e Ciências Humanas da Universidade de São Paulo. São Paulo, 2008. p. 211-213.

${ }^{53}$ Nesse sentido, cf. WANG, Daniel Wei Liang. Poder Judiciário e participação democrática nas políticas públicas de saúde. $104 \mathrm{f}$. Dissertação (Mestrado em Direito). Faculdade de Direito da Universidade de São Paulo. São Paulo, 2009. p. 32.

${ }^{54}$ Cf. RESENDE, Fabrício Contato Lopes. O papel do Poder Judiciário no controle da implementação de políticas públicas no Brasil: a política assistencial do artigo 20 da 
Em princípio, é possível conceber, aqui, que o Poder Judiciário - individual, coletiva ou abstratamente - corrija políticas públicas deficientes, suplemente políticas públicas insuficientes ou controle omissões estatais propriamente ditas (inexistência de política pública), de forma a compelir o Poder Público a cumprir adequadamente o seu dever prestacional.

Entretanto, mesmo nas ocasiões em que não determinam a entrega de uma prestação material, as decisões judiciais sobre direitos sociais podem influir na realidade, transformando-a. Uma atuação eficiente dos órgãos judicantes nesta matéria, além de tornar mais incerto e custoso o processo de tomada de decisões políticas, propicia naturalmente o fortalecimento da cidadania ativa, ampliando a participação democrática para além dos limites minimalistas da democracia representativa. ${ }^{55}$ Fala-se, dessa maneira, em contribuição indireta de juízes e tribunais para a realização da justiça distributiva, ${ }^{56}$ assertiva que reforça a ideia de que o Poder Judiciário pode ser um ambiente privilegiado para a discussão e deliberação sobre direitos fundamentais, nos limites da razão pública.

Em matéria de direitos sociais, as decisões judiciais podem abrir um importante canal de diálogo entre as instituições, sobretudo quando impõem aos Poderes Políticos o ônus de demonstrar, argumentativamente, a conveniência e razoabilidade das escolhas alocativas por eles realizadas. Além disso, a judicialização dos direitos sociais tem sempre a potencialidade de intensificar o debate público e criar uma mobilização

Lei n. 8.742/93. 161 f. Dissertação (Mestrado em Direito). Faculdade de Direito da Universidade de São Paulo. São Paulo, 2010. p. 70.

55 ARANTES, Rogério Bastos; KERCHE, Fábio. Judiciário e democracia no Brasil. Novos Estudos CEBRAP, São Paulo, v. 54, p. 27-41, 1999. p. 31.

${ }^{56}$ Inúmeras formas de contribuição indireta do Judiciário para a transformação social são apontadas na literatura. Uma dessas formas seria a criação de uma espécie de "linguagem sobre direitos fundamentais", produto da impregnação do discurso político pelos argumentos e pelas técnicas utilizados pelo Judiciário na resolução de litígios constitucionais (a regra da proporcionalidade, por exemplo). A construção dessa linguagem teria a virtude de contribuir especialmente para a sedimentação de critérios homogêneos de racionalidade e eficiência no processo de avaliação das políticas públicas, além de elevar a qualidade das deliberações públicas, estimular o diálogo entre os poderes e tornar mais transparentes as interações havidas entre eles. Cf., no ponto, RESENDE, Fabrício Contato Lopes. O papel do Poder Judiciário no controle da implementação de políticas públicas no Brasil: a política assistencial do artigo 20 da Lei n. 8.742/93. 161 f. Dissertação (Mestrado em Direito). Faculdade de Direito da Universidade de São Paulo. São Paulo, 2010. p. 71-72. 
política em torno das questões demandadas. ${ }^{57}$ Os grupos sociais vulneráveis e menos favorecidos, nesse contexto, podem ter no Poder Judiciário a via institucional mais efetiva, célere e barata para a concretização de suas reivindicações. ${ }^{58}$

Sem embargo, o desempenho deliberativo do Judiciário e as características estruturais dessa instituição podem resultar na não realização da justiça distributiva desejada. Há diversas variáveis que interferem com a qualidade da atuação do Judiciário em demandas relativas à efetivação de direitos sociais prestacionais. A questão da acessibilidade à Justiça, por exemplo, implica o problema de se levar ao conhecimento do Judiciário as demandas que dizem respeito às pessoas pobres e menos instruídas. A dificuldade (física e jurídica) de acesso à Justiça pode ser, nesse sentido, um fator de agravamento da marginalização social. ${ }^{59}$ Outro exemplo: a forma pela qual juízes e tribunais deliberam sobre políticas públicas pode influenciar os resultados do programa de macrojustiça implementado pelo governo, produzindo frustração do plano de universalização de determinadas prestações materiais e, colateralmente, vulneração dos preceitos constitucionais que pautam a atuação da Administração Pública. Com efeito, uma intervenção exacerbada do Judiciário no âmbito das políticas universalistas, além de levantar a suspeita de ilegitimidade democrática, pode trazer consequências indesejadas, como a distribuição dos bens e serviços apenas entre aqueles poucos que têm acesso às vias judiciais e a desestruturação do plano de ação voltado para a concretização dos direitos a prestações - contrariando os princípios constitucionais da impessoalidade e da eficiência administrativa, entre outros.

\section{CONSIDERAÇÕES FINAIS}

57 GLOPPEN, Siri. Courts and social transformation: an analytical transformation. In: GARGARELlA, Roberto; DOMINGO, Pilar; ROUX, Theunis (Orgs.). Courts and social transformation in new democracies: an institutional voice for the poor? Aldershot: Ashgate, p. 35-59, 2006. p. 42.

${ }^{58}$ WANG, Daniel Wei Liang. Poder Judiciário e participação democrática nas políticas públicas de saúde. 104 f. Dissertação (Mestrado em Direito). Faculdade de Direito da Universidade de São Paulo. São Paulo, 2009. p. 34.

${ }^{59} \mathrm{Cf}$, acerca do direito fundamental de acesso à Justiça, BARCELLOS, Ana Paula de. Eficácia jurídica dos princípios constitucionais: o princípio da dignidade da pessoa humana. 2. ed. Rio de Janeiro: Renovar, 2008. p. 325-333. 
Na moldura da teoria dos diálogos institucionais, é um equívoco colocar a contribuição de um dos Poderes acima da participação dos demais. As instituições são parceiras, e não adversárias, na construção de soluções para os problemas constitucionais. Em matéria de direitos sociais, isso implica defender uma "postura judicial flexível e moderada, que deverá variar conforme as razões e contrarrazões apresentados em cada caso levado à sua apreciação”.

A abertura do procedimento judicial para o diálogo com as demais instituições e com os atores sociais, nesse sentido, parece ser fundamental para legitimar e melhor efetivar as escolhas alocativas realizadas pelo Judiciário. As decisões sobre alocação de recursos públicos, como visto, possuem um caráter discricionário, dada a inexistência de um critério único a partir do qual possam ser tomadas. Além disso, tais decisões possuem uma natureza trágica, dramática, uma vez que envolvem uma escolha acerca do que deve ser ou não atendido num cenário de escassez de recursos e de crescimento das demandas sociais e econômicas.

A democratização do procedimento deliberativo, ao permitir a prévia manifestação de todos os diretamente interessados na decisão a ser proferida, ameniza a chamada "dificuldade contramajoritária", contribuindo para suprir o déficit democrático da medida adotada pelo Poder Judiciário. Além disso, ela ainda enseja que as políticas públicas se tornem mais eficientes precisamente para os mais interessados nelas, por meio da cobrança, da fiscalização e da troca de conhecimentos.

\section{REFERÊNCIAS BIBLIOGRÁFICAS}

ABRAMOVICH, Víctor; COURTIS, Christian. Los derechos sociales como derechos exigibles. Madrid: Trotta, 2002.

ACCA, Thiago dos Santos. Uma análise da doutrina brasileira dos direitos sociais: saúde, educação e moradia entre os anos de 1964 e 2006. 179 f. Dissertação (Mestrado em Direito). Faculdade de Direito da Universidade de São Paulo. São Paulo, 2008.

ALEXY, Robert. Teoria dos direitos fundamentais. Tradução de Virgílio Afonso da Silva. São Paulo: Malheiros, 2008.

AMARAL, Gustavo. Direito, escassez \& escolha: em busca de critérios jurídicos para lidar com a escassez de recursos e as decisões trágicas. Rio de Janeiro: Renovar, 2001. 
ANDRADE, José Carlos Vieira de. Os direitos fundamentais na Constituição portuguesa de 1976. Coimbra: Almedina, 1987.

ARANTES, Rogério Bastos; KERCHE, Fábio. Judiciário e democracia no Brasil. Novos Estudos CEBRAP, São Paulo, v. 54, p. 27-41, 1999.

BARCELLOS, Ana Paula de. Eficácia jurídica dos princípios constitucionais: o princípio da dignidade da pessoa humana. 2. ed. Rio de Janeiro: Renovar, 2008.

BOROWSKI, Martin. La estructura de los derechos fundamentales. Tradução de Carlos Bernal Pulido. Bogotá: Universidad Externado de Colombia, 2003.

CAMARGO, José Márcio. Focalizar versus universalizar. Políticas sociais - acompanhamentos e análises (IPEA), Rio de Janeiro, v. 7, p. 117-121, ago. 2003.

CANOTILHO, J.J. Gomes. Estudos sobre direitos fundamentais. Coimbra: Coimbra Ed., 2008.

COHEN, Joshua. Deliberation and democratic legitimacy. In: MATREVERS, Derek; PIKE, Jon (Orgs.). Debates in contemporary political philosophy: an anthology. New York: Routledge: Open University, p. 342-360, 2003.

DIXON, Rosalind. Creating dialogue about socioeconomic rights: strong versus weak form judicial review revisited. International Journal of Constitutional Law, v. 5, n. 3, p. 391-418, 2007.

DWORKIN, Ronald. Uma questão de princípio. Trad. Luís Carlos Borges. São Paulo: Martins Fontes, 2001.

. Levando os direitos a sério. São Paulo: Martins Fontes, 2002.

ESTLUND, David. Jeremy Waldron on law and disagreement. Philosophical Studies, v. 99, p. 111-128, 2000.

GARGARELLA, Roberto. Should deliberative democrats defend the judicial enforcement of social rights? In: BESSON, Samantha; MARTÍ, José Luis (Orgs.). Deliberative democracy and its discontents. Aldershot: Ashgate, p. 233-252, 2006.

. Theories of democracy, the Judiciary, and social rights. In: GARGARELLA, Roberto; DOMINGO, Pilar; ROUX, Theunis (Orgs.).

Courts and social transformation in new democracies: an institutional voice for the poor? Aldershot: Ashgate, p. 13-34, 2006.

GLOPPEN, Siri. Courts and social transformation: an analytical transformation. In: GARGARELLA, Roberto; DOMINGO, Pilar; ROUX, Theunis (Orgs.). Courts and social transformation in 
new democracies: an institutional voice for the poor? Aldershot: Ashgate, p. 35-59, 2006.

HABERMAS, Jürgen. Direito e democracia: entre facticidade e validade. Trad. Flávio Beno Siebeneichler. Rio de Janeiro: Tempo Brasileiro, 1997, v. 1.

Direito e democracia: entre facticidade e validade. Trad. Flávio Beno Siebeneichler. Rio de Janeiro: Tempo Brasileiro, 1997, v. 2.

. Constitutional democracy: a paradoxical union of contradictory principles? Political Theory, v. 29, n. 6, p. 766-781, dez. 2001.

HOLMES, Stephen; SUNSTEIN, Cass. The cost of rights: Why Liberty Depends on Taxes. New York and London: W. M. Norton, 1999.

KRELL, Andreas J. Direitos sociais e o controle judicial no Brasil e na Alemanha: os (des)caminhos de um direito constitucional “comparado". Porto Alegre: Sergio Antonio Fabris Editor, 2002.

LOPES, José Reinaldo de Lima. Em torno da "reserva do possível". In: SARLET, Ingo Wolfgang; TIMM, Luciano Benetti (Orgs.). Direitos fundamentais, orçamento e "reserva do possível". 2. ed. Porto Alegre: Livraria do Advogado, p. 155-173, 2010.

MENDES, Conrado Hübner. Controle de constitucionalidade e democracia. Rio de Janeiro: Elsevier, 2008.

Deliberação, separação dos poderes e direitos fundamentais. 267 f. Tese (Doutorado em Ciência Política). Faculdade de Filosofia, Letras e Ciências Humanas da Universidade de São Paulo. São Paulo, 2008.

MICHELMAN, Frank I. Brennan and democracy. New Jersey: Princeton University, 1999.

MIRANDA, Jorge. Manual de direito constitucional. 4. ed. Coimbra: Coimbra, t. IV, 1998.

NINO, Carlos Santiago.The constitution of deliberative democracy. Londres: Yale University Press, 1996.

OLSEN, Ana Carolina Lopes. A eficácia dos direitos fundamentais sociais frente à reserva do possível. $387 \mathrm{f}$. Dissertação (Mestrado em Direito). Setor de Ciências Jurídicas da Universidade Federal do Paraná. Curitiba, 2006.

RAWLS, John. O liberalismo político. Trad. Dinah de Abreu Azevedo. 2. ed. São Paulo: Ática, 2000.

RESENDE, Fabrício Contato Lopes. O papel do Poder Judiciário no controle da implementação de políticas públicas no Brasil: a política assistencial do artigo 20 da Lei n. 8.742/93. $161 \mathrm{f}$. 
Dissertação (Mestrado em Direito). Faculdade de Direito da Universidade de São Paulo. São Paulo, 2010.

SARLET, Ingo Wolfgang. A eficácia dos direitos fundamentais: uma teoria geral dos direitos fundamentais na perspectiva constitucional. 10. ed. Porto Alegre: Livraria do Advogado, 2009.

SCAFF, Fernando Facury. Sentenças aditivas, direitos sociais e reserva do possível. In: SARLET, Ingo Wolfgang; TIMM, Luciano Benetti (orgs.). Direitos fundamentais, orçamento e "reserva do possível". 2. ed. Porto Alegre: Livraria do Advogado, 2010.

SILVA, José Afonso da. Aplicabilidade das normas constitucionais. 7. ed. São Paulo: Malheiros, 2009.

SILVA, Virgílio Afonso da. A constitucionalização do direito: os direitos fundamentais nas relações entre particulares. São Paulo: Malheiros, 2008.

. O Judiciário e as políticas públicas: entre transformação social e o obstáculos à realização dos direitos sociais. In: SOUZA NETO, Cláudio Pereira de; SARMENTO, Daniel. Direitos sociais: fundamentação, judicialização e direitos sociais em espécie. Rio de Janeiro: Lumen Juris, 2008.

. O STF e o controle de constitucionalidade: deliberação, diálogo e razão pública. Revista de direito administrativo, v. 250, p. 197227, 2009.

SUNSTEIN, Cass. Social and economic rights? Lessons from South Africa. John M. Olin Law \& Economics Working Paper, Chicago, n. 124, 2001.

TAYLOR, Matthew M. O Judiciário e as políticas públicas no Brasil. Revista de Ciências Sociais, Rio de Janeiro, v. 50, n. 2, p. 229257, 2007.

TORRES, Ricardo Lobo. Tratado de direito constitucional financeiro e tributário: o orçamento na Constituição. 2. ed. Rio de Janeiro: Renovar, 2000, v. 5.

TROPER, Michel. The logic of justification of judicial review. International Journal of Constitutional Law, v. 1, n. 1, p. 1063-1080, jan. 2003.

VERÍSSIMO, Marcos Paulo. A judicialização dos conflitos de justiça distributiva no Brasil: o processo judicial no pós-1988. $264 \mathrm{f}$. Tese (Doutorado em Direito). Faculdade de Direito da Universidade de São Paulo, 2006. 
WALDRON, Jeremy. Law and disagreement. Oxford: Oxford University, 1999.

WANG, Daniel Wei Liang. Poder Judiciário e participação democrática nas políticas públicas de saúde. $104 \mathrm{f}$. Dissertação (Mestrado em Direito). Faculdade de Direito da Universidade de São Paulo. São Paulo, 2009. 